\title{
A Relação Médico-Paciente e o Cuidado Humano: Subsídios para Promoção da Educação Médica
}

\author{
The Physician-Patient Relationship and \\ Human Care: a contribution to the \\ promotion of medical education
}

Suely Grosseman ${ }^{1}$ Zulcica Maria Patrício²

PAIAVRAS-CHAVE:

- Relaçōes Mléclico-Paciente;

- SaĹde Holistica;

- Satistaçăo no Emprego:

- Educaçàn Médica.

KEY-IVORDS:

-Physician-Parient Relations:

-Holistic Health;

- Joh Saijsfaccion;

- Educarion, Medical

Reccljido cm: $25 / 11 / 2003$

Recearnutinalo an: 27/02/2004

Aprovadoen): 19/05/2004

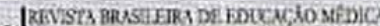

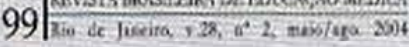

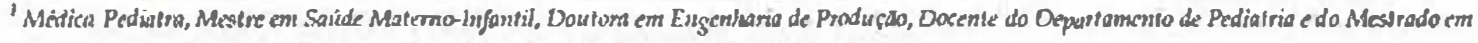
Ciencies Medilicas dn Uniocrsidade Faderal de Santa Cafarma (UIFSC). Florianopolis, Bnasit.

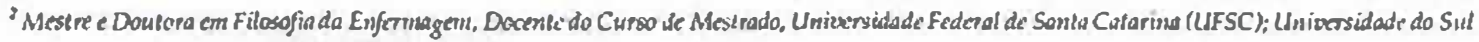
de Santa Catarima (Unisul), Flonianbyolis, Brasil. 


\section{INTRODUÇĀO}

O conteuido deste artigo teve como fonte de dados a tese de doutorado' Satisfação com o traballho: do desejo ì realidade de ser médico, cujo objetivo era compreender, junto a profissionais médicos, os significados do desejo de ser médico e a satisfação com a realidade do trabalho.

Para alcançar tal objetivo, o método da pesquisa foi o qualitativo ${ }^{23,4,5}$, e o tipo de estudo o Multicasos ${ }^{2.6}, \operatorname{com}^{25}$ médicos (pediatras, clínicos, cirurgiōes, ginecologistas/obstetras e médicos da Saúde Pública), de ambos os sexos, formados há mais de 15 anos, residentes em Santa Catarina (Brasil). A pesquisa atendeu os princípios de eticidade, preconizados na Resoluçāo 196/96 do Conselho Nacional de Saúde: os objetivos do estudo e os benefícios que dele poderiam advir foram apresentados, verbalmente e por escrito, aos pesquisados, que, então, foram convidados a participar do estudo. Após aceitação, eles receberam, para leitura, o Termo de Consentimento Livre e Esclarecido (TCLE), que continha os objetivos e outros detalhes da pesquisa. Nesse Termo, a pesquisadora se comprometia a garantir o anonimato dos pesquisados e fornecia telefones de contato, caso eles quisessem desistir, a qualquer momento, de participar da pesquisa. Então, lhes foi solicitada a assinatura do Termo e a escolha de um codinome, para preservação do anonimato ${ }^{7}$. Os dados foram coletados por entrevista semi-estruturada em profundidade (subsidiada por recursos de simbolização) e analisados pela técnica "Análise-Reflexão-Sintese"1.5.8.

Com esse processo, foram encontrados sete grandes temas: "A potência e o potencial do desejo de ser médico" (processo de construção do desejo de ser médico); " $\Lambda$ 'perda da poesia' na formação acadêmica" (processo de formação acadêmica); "A satisfaçāo de ser médico" (fatores que promovem a satisfação do médico com seu trabalho); "O conflito com os desejos altruístas, no exercício da profissāo" (fatores psicológicos do cotidiano que limitam a satisfaçao profissional); "Entre o curar e o cuidar" (estratégias elaboradas frente às limitaçð̄es sentidas no cotidiano); "Desilusão com os desejos de reconhecimento e boa qualidade de vida" (outros fatores de insatisfação) e "Dos desejos do passado aos desejos para o futuro" (expectativas do passado e para o futuro).

O componente "interação médico-paciente" permeou esses temas, expressando-se como importante dimensāo na construção cotidiana do "ser médico" e na satisfação com a profissão, tendo como referência os significados que originaram o desejo profissional e as expectativas para a vida futura, com forte influência do processo de formação acadêmica.

Entendendo que é de grande importância estudar a relação médico-paciente, o objetivo deste artigo é trazer dados desse tema, esperando gerar reflexōes que estimulem, ind ividual e coletivamente, a revisão de atitudes aprendidas e ensinadas durante a formação e a prática médica, na perspectiva de inter-relaçũes que promovam maior competência técnicohumanistica do profissional, cuja qualidade possa promover a satisfaçāo do paciente com o médico, a do médico com seu trabalho, a do aluno com o docente e a do docente com sua prática pedagógica.

Partindo dessas consideraçĭes e seguindo princípios da pesquisa qualitativa, o tema proposto é apresentado a partir de dados empíricos, relativos a depoimentos selecionados do conjunto de dados dos participantes do estudo' e analisados com apoio da literatura.

\section{A IMPORTÂNCIA DA FORMAÇĀO ACADÊMICA NA INTERAÇĀO MEDICO-PACIENTE}

Um dos principais significados para o emergir do desejo de ser médico, nos profissionais do estudo de Grosseman', foi o desejo de curar, ajudar, salvar ou cuidar de outros seres humanos. Muitos deles pensavam que a promoçāo do bemestar de outros seres humanos thes proporcionaria a realização profissional e pessoal, pois, como veiculado por desejos coletivos e transmitido pela sociedade, o exercício adequado da medicina acarretaria reconhecimento social c financeiro, e boa qualidade de vida.

No cotidiano do trabalho, a interação médico-paciente tem importante papel na satisfação profissional desses médicos, gerando energia e disposiçāo, e contribuindo para que eles reflitam sobre a vida do "outro" e a própria vida:

1 profissño me satisfaz bastante pela coisa do auxiliar (...) a ponto de ver que você est́́ cansado, depois de um plantĩo, ou não acorda legal, não estí disposto a atender, mas, à medida que comef̧a a atender, vai mudando. A tua disposif̧ño melhora pela propria interaf̧ão com o indivíduo que está un tun frente. Então, isto dá uma satisfaçño muito grande (...).

Os meus vinte e poucos anos de profissdo já me deram a oportunidade de um monte de pessoas sentarem na minha frente (...). Se um por cento daquelas pessons (...) deixou alguma coisa para mim, eu sou uma pesson bastante rica, porque (...) ela sempre deixa alguma coisa bon parn você, se vocé estiver aberto para receber (...). Só médico vive isso. (...) também, lu abres a oportunidade de olhar o mundo, você cresce com isso. Você olha a outra pesson e diz: 'Puxa, o que eu estou fazendo da minha vida!'. Você dá um conselho parn uma pesson: ' $\wedge$ senhora tem que caminhar'. Aquilo volta para mime digo: 'Puxa, tenho que caminhar'. 
Nessa perspectiva, a formação acadêmica vivenciada por esses profissionais, por nāo ter valorizado em seu contexto a competência relativa ao relacionamento interpessoal, limitou a expressāo de parte de seus desejos, o que precipitou, nesta época, reflexūes sobre os ideais da escolha da profissão.

Entre as limitaçōes apontadas na formaçāo, destacaramse: o aprendizado centrado no diagnóstico e tratamento de doenças, principalmente em sala de aula e no conlexto hospitalar; oportunidades insuficientes de interagir com a comunidade para compreender sua cultura e seus determinantes saúde-doença; a não valorização de atitudes voltadas às necessidades do ser humano, no processo de ensinar-aprender a interaçāo médico-paciente:

(...) o próprio curriculo, que me distancion cada vez mais daquela insagem de médico que eu tinhra, na adolescência (...). Em termos de currículo, eu acho uma catéstrofe porque (...) o curso de medicina é o exercicio de tirar você do paciente, de tirar você da populaşăo, do 'desexercicio' da medicima (...). Vocì tem um monte de matérins e tem uma nula prótica com 15 pessons. $E$. ai, te jogam um paciente enfermo (...) ell vejo leito hospitalar. Eu nāo vejo determinaçāo da doença (...).Entđ̃o, há uma 'desinserçăo' do currículo com a realidade da populaçāo, para determinação da doenı̧a (....).Porque a nossa prática tem que se dar principalmente dentro da população. Porque $i$ ali que se dá o processo sniude-doença.

A faculdade te ensina o que é um abdômen agudo, que aquela cama ló tem um paciente com apendicite e tal. O conhecimento hoje é tanto. que n freuldande uno tem tempo de colocat o aluno diante do ser humano mesmo. Ela nāo ensina isso. Você vai aprender na vida... vai lapidando isso.

(...) a nossa faculdade, do ponto de vista relacional, é muito complicada. Acho o caos (...). Eles preparam para o camarada saber $e$ is para a vida profissional, sem nenhumma base de relaçño humana. Nenhumma, mada, zero! (...) para traballiar isso, cada semestre que passasse, deveriam colocar pessons competentes para traballhar a parte de relaçño do aluno com a vida dele fora da academia também. A relaçāo do aluno com o paciente é umma coisa muita mecînica também; tem que ter uma outra abordagem. A relaçāo médico-meio é muito complicada. Ele (o aluno) nāo se prepara uada. Ele é jogado feito um 'cachorro no meio da arena' e ele jí sai de armas em pumho.

Teve umen pesson que me falou que o estudante entra muito idealista e sai um cinico porque (...) o modelo è muito tícnico, esquece a viș̄o geral, a visāo humana mesmo. Cínico, no sentido de fingir que lida com humanos (...) Então, no infício, na aula de anamnese, ele se preocupa até em se apresentar, pede licença, explica para os pacientes o que está acontecendo. E quando ele sai. já chega una maca, jó tira o lençol do cara, nem fala com o crara, uma coisa muito mecânica, como se ali estivesse um amontoado de brgzios deitados naquela maca.

Os professores que ensinaram a gente a tocar no paciente e a chamar o paciente pelo nome, ao invés da doença, foram poucos. Tnnto $\dot{c}$ gue cada um de nós tem um professor desses em mente. Eu acho que isso ė o mais importante no médico. Está msis que provado. Se tiver essa parte, a gente consegue curar muito mais do que com medicamento (...).

Na verdade, o curso de medicina foi:, para mim, a desmistificaçño da medicina (...). Daquilo que eu imaginava de ser médico. Ele foi me tirando da minha poesia.

Os profissionais do estudo também ressaltaram o sentimento de negaçảo de sua vulnerabilidade no cotidiano do processo ensinar-aprender já na própria relaçāo docente-discente, e como isso repercutia em sua qualidade de vida.

Eu acho unu absurdo o que fnzem com a gente na faculdade de medicina. Eles criam a gente assim: 'Médico nāo pode comer, médico nส̃o tem fome, médico uño tem dor, médico nño fica doente'. Quantos pacientes falam: 'Mas médico também fica doente?' (...). Entāo, eu passei batido a minhıa vida. Anos que nem um trator e "הo tenho drividas de que médico é prepotente (...), a gente é criado para isso.

Por conta da "inabilidade" na interação com o paciente, esses médicos, quando em situações de difícil manejo, como, por exemplo, de grande sofrimento e morte iminente, sentem mais dificuldades relacionais, o que gera neles grande sofrimento.

U'm paciente (...) em fase terminal è uma criança (...) e a medicima nส̃o vai dar conta de salvar (...). Isso nĩo me frustra do ponto de vista de onipotência (...) O que me preocupa é como vou conseguir dar o apoio adequado nessas horas (...) e é o que me macluca mais no dia-a-dia. (...) do ponto de vista profissional, a gente nĩo ¿ preparado nem na escola, nem na vida profissional.

O médico sabe lidar com a morte? Nāo sabe. O paciente terminal é abandonado. O médico faz oncologia, cu tenho um residente que estí fazendo oncologia no Rio. Eu perguntei: 'Vocês 
têm algum apoio psicológico?’. Nāo, nenhumu. É paciente que morre, paciente que morre, paciente que morre. O que $\dot{e}$ que ele vai fazer se näo tem preparo? Endurece diante da vida (...).

Esses depoimentos levam a considerar que, durante a formação acadêmica, os profissionais aprenderam a buscar o objeto "doença" nas pessoas e sentiram falta de abordagens que estimulassem seu potencial de se relacionar com o outro. Além das limitaçōes que apontaram no processo ensino-aprendizagem no que se refere à subjetividade do outro, também expressaram o aprendizado da negação da própria subjetividade, em especial a expressão de seus sentimentos.

Atualmente, os médicos têm se deparado com críticas da sociedade. Dunning ${ }^{9}$ pondera que um dos fatores que têm contribuido para isto é que, hoje, uma população mais bem informada requisita maior consideração e transparência dos profissionais médicos, além de modelos profissionais seguros. Esse autor remete a William Osler, que, em 1903, já exclamava, em relação aos médicos, que "metade de nós está cega, poucos de nós sentimos e todos nós estamos surdos". Neste sentido, Zimerman ${ }^{10}$ enfatiza a necessidade de o médico se esforçar para compreender o paciente, pois "nāo há nada pior no ato médico do que o 'diálogo de surdos' da incomunicação, razāo por que é da máxima importância que o médico possa traduzir a linguagem do paciente, quando ela vem trazida sob signos primitivos".

Segundo Ballint", na formação acadêmica prepara-se o médico para "catequizar" o paciente a seguir as ordens médicas, como se fosse uma religiāo, à qual o paciente deveria aderir pela fé no possuidor do saber. Entretanto, o autor ressalta que a doença não pọde ser compreendida como um fenômeno isolado, mas sim em relação à vida do individuo e seu ambiente.

Para Crema, "a doença é um ruido indicativo de nossas contradiçōes. Necessitamos escutá-lo e compreendê-lo para, só entāo, eliminá-lo"12. Considerando que a doença é uma forma de o indivíduo explicitar conflitos internos, Ballint", assim como Crema, chama atenção para o valor que esta doença representa, tanto para o individuo que adoece como para o médico, para lançar luz ao conflito que ela expressa.

Aprender a trabalhar com a subjetividade é fundamental para o desenvolvimento de uma relação médico-paciente construtiva, o que vem a definir a qualidade da prática médica. Ballint" chega a afirmar que "o remédio mais usado em medicina é o próprio médico, o qual, como os demais medicamentos, precisa ser conhecido em sua posologia, reaçōes colaterais e toxicidade".

A relação médico-paciente, para Entralgo ${ }^{13,14}$, é uma forma singular de amizade ser humano/ser humano, que deve abranger a benevolência (querer o bem do outro); a benedicência (falar bem do outro, na medida em que pode fazê-lo sem mentir); a beneficência (aceitar lealmente o que o outro é, ajudando-o delicadamente a que seja o que deve ser); e a benefidecência, que é a efusāo - expansāo de afeto - em direção ao outro, para compartilhar com ele algo que lhe pertence intimamente, que se dá em confidência e vai permitir aos dois transformar a relaçāo dual em dinidica.

$\mathrm{O}$ tipo de interação que se estabelece entre o médico e o paciente depende de como o médico vê o ser humano que o procura. Neste sentido, Guareschi ${ }^{15}$ explana que as relaçōes entre os seres humanos são influenciadas pela visāo predominante do contexto histórico-social em que eles estāo inseridos. Quando a visāo da sociedade é individualista, muitas vezes, o ser humano tende a considerar o "outro" como pouco importante para o seu próprio crescimento, e o tipo de relação que se estabelece se dá de forma que cada um tenta ver o que pode "tirar" do outro, ao invés de vê-lo como complementar. Quando a visão é totalitária, o ser humano passa a ser secundário ("uma peça na máquina"), havendo perda da individualidade, e a forma de relacionamento que se estabelece também leva pouco em consideração o "outro", pois a importância está centrada no sistema, geralmente muito burocratizado.

Guareschii ${ }^{15}$ pondera que, para o estabelecimento de relaçōes construtivas de diálogo e uma verdadeira relação interpessoal, é necessário valorizar o "outro" em sua identidade, respeitando seus valores e compartilhando suas experiências, considerando-o alguém essencial à própria existência. Por meio desta visāo, o ser humano passa a sentir necessidade de escutar o "outro", pois este, ainda que distinto, contribui para o próprio desenvolvimento pessoal. $O$ autor esclarece que somente neste tipo de relação pode-se considerar a ética e o respeito entre os seres humanos.

Atualmente, na sociedade ocidental, a visão tem sido mais centrada no individualismo e, como conseqüência, o hábito de escutar tem sido pouco enfatizado no cotidiano das interaçठ̋es entre os seres humanos. Entretanto, este escutar precisa ser resgatado, pois, como afirma Alves: "O que as pessoas mais desejam é alguém que as escute de maneira calma e tranqüila. Em silêncio. Sem dar conselhos (...) A gente ama nāo é a pessoa que fala bonito. E a pessoa que escuta bonito"16.

No caso da interação médico-paciente, Videla ${ }^{17}$ comenta que os pacientes têm fome de solidariedade porque a enfermidade, muitas vezes, humilha, corrói o sentido do "eu", tornando-os vulneráveis à palavra do médico e, portanto, este deve cultivar a flexibilidade e a tole rância para honrar o ponto de vista dos pacientes. $O$ autor esclarece que o médico pode saciar a fome de solidariedade do paciente com conversas te- 
rapêuticas e a tentativa de resgate de uma "esperança ética", que, inclusive, pode ajudar a instalar no paciente uma busca interna de cura.

Fazendo-se uma leitura dialética dos dados empiricos, pode-se observar que o contexto satisfaçāo-insatisfaçāo, por ter gerado contradiçōes, estimulou transformaçōes e fez emergir um movimento particular de reflexāo, resultando em novas sínteses que incorporaram componentes do cuidado, como aparece nos depoimentos que se seguem:

Eu tive contato com um professor (...) que me introduziu aqueIn imagem diferente do que é uma pesson, do que é a doença. Pela primeirn vez, 18 anos de formada, cu comecei a aprender a atender um ser humano (...) O médico mesmo, ele atende um paciente que está doente, nem sempre uma doença que precise de medicamento; muitas vezes, $\hat{\varepsilon}$ uma doença que é da famślia ou de uma vida mal vivida. E como é que a gente vai interagir nisso? O poder de curn é limitado... Você pode fazer muita coisa pelo paciente, sem curá-lo. Ajudar, cuidar... E, quando você uño curn e cuidn, eu acho que o sentido tanto do cuidado do docnte como o do médico se complementam.

A gente dá outras coisas. 1 gente tem um envolvimento diferente (...) além de medicar a dor, conversa com o paciente, procura reabilití-lo dentro daqucin circunstâncin: a familin a ele $e$ ele à familia. Entảo, a gente consegue conversar até sobre a doença com a famillia e consegue tirar coisas de umı docuçn, que a dor dimimi, mesmo sem ser com analgésico. Você, inclusive, preparn o caminho parn a morte, até... sem grandes recursos. Basta conversar. E, muitas vezes, a gente năo consegue dizer nada e a gente abraça.

Analisando-se qualitativamente os dados empiricos e teóricos apresentados, à luz da literatura sobre interação humana na assistência à saúde e qualidade de vida dos envolvidos nesse processo, surgem categorias que representam a qualidade da interação médico-paciente e a qualidade da interaçāo docente-aluno de medicina. Essas categorias, por sua vez, expressam componentes do construto do cuidado humano, abordados nos estudos de Leininger ${ }^{18.19}$.

Leininger desenvolveu a Teoria do Cuidado Transcultural, voltada para o cuidado da saúde do ser humano, na área da antropologia. A autora chama atençāo para o "cuidado humanizado", demonstrando a importância de considerar, na assistência, o ser humano em sua integralidade, diversidade e unicidade, contemplando suas crenças, seus valores, conhecimentos e suas práticas de saúde, o que se expressa pelos componentes do care-caring (cuidar-cuidando) ${ }^{19}$.
Patrício, partindo de dados de experiências de campo na área da saúde em contextos brasileiros, estudou essa teoria $\mathrm{e}$ ampliou esse construto, com base em outros teoristas sobre "cuidado humano" ${ }^{210}$ e em Gramsci" , tendo em vista a saúde como bem viver individual-coletivo que envolve subjetividade, ambiente, participaçāo, cidadania e educaçāo, ao qual denominou "processo de cuidar-cuidado sócio-cultural" ${ }^{\prime 22}$. Posteriormente, a autora incorporou outras concepçōes, que ampliaram a compreensāo do ser humano, na construçāo individual-coletiva do processo saúde-doença, que evidenciaram ainda mais a qualidade das interaçōes como mediadoras da construçāo desse processo e da própria qualidade de vida individual-coletiva, denominando-o "Referencial do Cuidado Holistico-Ecológico"s.

Nesse contexto, para a autora, o "cuidado da vida" "cultivar a vida" - seja para promover a saúde ou para tratar problemas que limitam o processo de viver saudável pressupōe a integraçāo entre razāo e sensibilidade como atributo da qualidade das interaçōes que o ser humano desenvolve com outros seres humanos e com a natureza nāo cultural.

Assim, o processo de cuidar envolve componentes éticos e estéticos de bem viver individual-coletivo num dado ambiente, tendo em vista a complexidade e diversidade das múltiplas interconexōes que se constroem na história de vida, desde o primeiro ambiente, o útero matemo. Nesse processo de cuidar, o profissional da saúde, além de considerar os componentes culturais, também valoriza as expectativas, sentimentos e desejos dos seres humanos envolvidos na situaçāo em estudo. Eum diálogo de escuta e troca de universos culturais e afetivos, que resulta em transformaçōes nāo somente naquele que é cuidado, mas também no cuidador ${ }^{5.22}$.

$\mathrm{Na}$ expectativa de melhorar a qualidade da interaçāo méd ico-paciente e ainda promover satisfaçāo, a reflexāo crítica - o questionamento ético - acerca dos dados empíricoteóricos até aqui apresentados evidencia a importância da qualidade das interaçōes que se desenvolvem no processo ensinar-aprender, nos diversos cenários do cotidiano, na formaçāo acadêmica dos cursos de medicina. Até porquue nada ensina tāo bem quanto o "discurso testemunhado", e isso o aluno precisa ver na relaçāo docente-paciente, docente-docente e docente-discente. Este processo favorece uma aprendizagem mais tranqüila, mais saudável, mais humana e, inclusive, uma aprendizagem para o autocuidado.

As autoras concebem, nesse momento, que o paciente deseja e tem o direito de ser cuidado no processo de ser assistido pelo médico e que o aluno também deseja e tem o direito de ser cuidado no processo de ensinar-aprender medicina. 
As novas Diretrizes Curriculares ${ }^{23}$, fruto de esforços conjuntos de diversos setores envolvidos e comprometidos com o ensino e a prática médica, já incorporam essa filosofia, representando um avanço conceitual conquistado. Nessa perspectiva, diversas escolas médicas no País têm inovado seu curriculo e divulgado suas experiências ${ }^{24,25,26,27}$.

\section{CONSIDERAÇÕES FINAIS}

Como propiciar que movimentos individuais se tornem coletivos? Como "sair da teoria para a prática"? Em outras palavras, como operacionalizar os conceitos e principios das novas Diretrizes?

Entendendo que todo projeto coletivo pressupōe uma transformaçāo individual, as autoras acreditam que seja necessário investir em processos pedagógicos que promovam atitudes de reflexão individual, com foco nos objetivos comuns.

Esse processo cria oportunidades para que cada participante se dê conta de seu próprio referencial e daquele dos demais, ou seja, das crenças, expectativas, práticas e sentimentos, desejos, valores e conhecimentos envolvidos no processo. Isso significa refletir sobre si mesmo, sobre dimensōes humanas, incluindo relaçōes cotidianas e com o mundo em geral, e o reflexo dessas situaçōes na qualidade de vida individualcoletiva $^{28}$

Nesta oportunidade, as autoras convidam os colegas a refletirem sobre a responsabilidade individual e coletiva de melhorar a qualidade das interaçōes educador-educando e médico-paciente, para que se promova, efetivamente, a satisfação mútua nestas relaçōes. $O$ contexto atual favorece o desencadeamento de reflexōes e mudanças de atitude.

Ereciso; para tanto, que os responsáveis pelo ensino médico comecem a considerar a diversidade e complexidade da subjetividade humana, no processo do ensinar-aprender e no processo do adoecer-curar, tendo em vista o importante papel que o médico tem como mediador destes processos.

Desta forma, pode ser vislumbrada uma medicina que integre ciência e arte, incorporando a dimensão estética, para consolidar uma prática profissional guiada por princípios de uma "ética do afetivo" futuro, ter médicos com mais capacidade de cuidar de sua própria saúde e também do paciente e da comunidade à qual pertencem.

\section{REFERENCIAS BIBLIOGRÁFICAS}

1. Grosseman S. Satisfação com o trabalho: do desejo à realidade de ser médico. [Tese]. Florianópolis: Universidade Federal de Santa Catarina; 2001.
2. Bogdan R, Biklen SK. Investigação qualitativa em educação: uma introdução à teoria e aos métodos. Porto: Porto; 1994.

3. Demo P. Metodologia científica em Ciências Sociais. São Paulo: Atlas; 1989.

4. Minayo MCS. O desafio do conhecimento: pesquisa qualitativa em saúde. São Paulo-Rio de Janeiro: HucitecAbrasco; 1993.

5. Patrício ZM. A dimensāo felicidade-prazer no processo de viver saudável: uma questão bioética numa abordagem holístico-ecológica. [Tese] Florianópolis: Universidade Federal de Santa Catarina, 1995.

6. Trivinōs ANS. Introdução à pesquisa em Ciências Sociais. São Paulo: Atlas; 1995.

7. Brasília. Ministério da Saúde. Conselho Nacional de Saúde. Resolução n 196/96 sobre Pesquisa Envolvendo Seres Humanos, de 10 de outubro de 1996.

8. Patrício ZM. Qualidade de vida do ser humano na perspectiva de novos paradigmas: possibilidades éticas e estéticas nas interaçōes ser humano-natureza-cotidiano-sociedade. In: Patricio ZM, Casagrande JL, Araújo MF. (orgs). Qualidade de vida do trabalhador: uma abordagem qualitativa do ser humano através de novos paradigmas. Florianópolis: PCA; 1999.

9. Dunning AJ. Status of the doctor - present and future. The Lancet 2000; 354 (SIV):2.

10. Zimerman DE. A formação psicológica do médico. In: Mello filho J (orgs). Psicossomática hoje. PortoAlegre (RS): Artes Médicas; 1992. p. 64-69.

11. Ballint M. O médico, seu paciente, e a doença. $2^{\text {t }}$ ed. Rio de Janeiro: Atheneu; 1988.

12. Crema R. Saúde e plenitude: um caminho para o ser. São Paulo: Summus; 1995: 105.

13. Entralgo PL. Historia de la medicina. Barcelona: Salvat; 1978.

14. Entralgo PL. Técnica, ética y amistad médica. In: Viveros MC (orgs). Medicina y sociedade. México: Fondo de Cultura Económica; 1994. p. 27-36.

15. Guareschi P. Alteridade e relação: uma perspectiva crítica. In: Arruda A (orgs). Representando a alteridade. Petrópolis (RJ): Vozes;1998. p. 149-161.

16. Alves R. O amor que acende a lua. Campinas, SP: Papirus: Speculum; 1993. p. 73.

17. Videla M. Prevención. Buenos Aires:Ediciones Cinco; 1998.

18. Leininger $M$. Teoria do cuidado transcultural: diversidade e universalidade. In: Anais do Seminário de Pesquisa em Enfermagem. Florianópolis:UFSC; 1985. 
19. Leininger M. Care constructs. Seminario de Pesquisa em Enfermagem. Florianópolis. Mimeos 1985.

20. Patrício ZM, Bohes EA. O significado do cuidar/cuidado. Florianópolis: UFSC. Mimeo 1988.

21. Gramsci A. Concepção Dialética da História. 7 ed. Rio de Janeiro: Civilização Brasileira; 1987.

22. Patrício ZM. A prática do cuidar-cuidado com a família da adolescente grávida e seu recém-nascido a través de uma marco conceitual de enfoque sócio-cultural. [Dissertação]. Florianópolis: UFSC; 1990.

23. Brasil. Ministério da Educação. Conselho Nacional de Educação. Càmara de Educaçāo Superior. Resoluçāo CNE/ CES 4/2001. Diário Oficial da União de Brasilia, 9 de nov: 2001, Seçāo 1: 38.

24. Congresso Brasileiro de Educação Médica, 39. Fórum de Avaliação das Escolas Médicas, 11. "Avaliaçōes no Ensino Médico: Impactos e Desafios"; 26-30 set 2001; Belém, Brasil. São Paulo: ABEM; 2001.

25. Comissāo Interinstitucional Nacional de Avaliação do Ensino Médico. Preparando a transformação da educação médica brasileira: projeto CINAEM III fase: relatório 19992000 / CINAEM. Piccini RX, Facchini LA, Santos RC (organizadores). Pelotas (RS): UFPel; 2000.
26. Campos JjB, Komatsu R. Novos currículos de medicina na FAMEMA e na UEL: uma construçāo permanente rumo à realidade presente e futura. Olho Mágico 2001 ; 8 (2): 8-14.

27. Venturelli J, Fiorini, VML. Programas Educacionais Inovadores em Escolas Médicas: capacitaçāo docente. Rev. Bras. Educ. Méd 2001; 25 (3): 7-21.

28. Patricio ZM. Nem talco nem diamante: a riqueza de um processo de ensino-aprendizagem participante na área da sexualidade-adolescência. Tex to \& Contexto; 1994 jul/dez; 3(2): 93-109.

29. Grosseman S, Patrício ZM. Do desejo à realidade de ser médico. Florianópolis; 2003. no prelo.

\section{Endereço para correspondência}

Suely Grosseman

Rua Amo Hoeschel, 121 - apt. 802 - Centro 88015-620 - Florianópolis — Santa Catarina e-mail: suely@linhalivre.net

Zuleica Maria Patricio

Rua das Araras, 396 - Lagoa

88062-075 - Florianópolis - Santa Catarina

e-mail: zucamp@hotmail.com 